\title{
(2) Tuning the Electronic Properties of Prussian Blue Analogues for Efficient Water Oxidation Electrocatalysis: Experimental and Computational Studies
}

\author{
Elif Pınar Alsaç, ${ }^{[\mathrm{a}]}$ Emine Ülker, ${ }^{[\mathrm{d}]}$ Satya Vijaya Kumar Nune, ${ }^{[\mathrm{a}]}$ Yavuz Dede, ${ }^{*[\mathrm{c}]}$ and \\ Ferdi Karadas*[a, b]
}

\begin{abstract}
Although several Prussian Blue analogues (PBAs) have been investigated as water oxidation catalysts, the field lacks a comprehensive study that focuses on the design of the ideal PBA for this purpose. Here, members of a series of PBAs with different cyanide precursors have been investigated to study the effect of hexacyanometal groups on their electrocatalytic water oxidation activities. Cyclic voltammetric, chronoamperometric, and chronopotentiometric measurements have revealed a close relationship between the
\end{abstract}

electron density of electroactive cobalt sites and electrocatalytic activity, which has also been confirmed by infrared and XPS studies. Furthermore, pH-dependent cyclic voltammetry and computational studies have been performed to gain insight into the catalytic mechanism and electronic structure of cyanide-based systems to identify possible intermediates and to assign the rate-determining step of the target process.

\section{Introduction}

Increase in energy demand has propelled the scientific community, particularly in the last two decades, to find alternative energy sources that will replace limited fossil-based fuels. ${ }^{[1]}$ Since solar energy that involves the production of $\mathrm{H}_{2}$ from water has been one of the most promising candidates among sustainable sources of energy, much effort has recently been devoted to investigating efficient methods for splitting water. $^{[2-7]}$ Since the water splitting process is mostly limited by the high overpotential of the oxygen evolution reaction (OER), many studies have been concerned with the introduction of novel catalysts that operate at low overpotentials. ${ }^{[8]}$ Many inorganic systems, including metal oxides, ${ }^{[9-12]}$ perovskites, ${ }^{[13-15]}$ amorphous materials, ${ }^{[16]}$ noble-metal-based materials, ${ }^{[17,18]}$ and metal-organic frameworks (MOFs) ${ }^{[19,20]}$ have been investigated

[a] E. P. Alsaç, Dr. S. V. K. Nune, Prof. Dr. F. Karadas

Department of Chemistry, Bilkent University, 06800 Ankara (Turkey)

E-mail:karadas@fen.bilkent.edu.tr

[b] Prof. Dr. F. Karadas

UNAM-Institute of Materials Science and Nanotechnology

Bilkent University, 06800 Ankara (Turkey)

[c] Prof. Y. Dede

Faculty of Science, Department of Chemistry

Gazi University, 06500, Ankara (Turkey)

E-mail:dede@gazi.edu.tr

[d] Prof. E. Ülker

Department of Chemistry, Faculty of Arts \& Sciences Recep Tayyip Erdogan University, 53100, Rize (Turkey)

$\square$ Supporting information and the ORCID identification number for the

(iD) author of this article can be found under: https://doi.org/10.1002/chem.201704933. as water oxidation catalysts (WOCs). Of these, cobalt oxides stand out due to their high catalytic activities, ${ }^{[21,22]}$ but are also associated with two main disadvantages: $:^{[23,24]}$ i) low stability and a high tendency to decompose in acidic media, ii) difficulty in correlation of their catalytic activities with structure due to their amorphous nature. Non-oxide materials have also attracted attention as WOCs due to their favorable characteristics, such as ease of preparation, stability over a wide $\mathrm{pH}$ range, and robustness during catalytic processes. ${ }^{[25]}$ Patzke et al. reported a carbodiimide-based material that could be used as a WOC, which is stable in acidic and neutral media. ${ }^{[26]}$ Members of a similar class of materials, metal dicyanamides, have also been shown to be promising candidates for water oxidation electrocatalysis. ${ }^{[2]}$ Cobalt hexacyanoferrates, members of the Prussian Blue analogue (PBA) family, are also exceptional candidates for electrocatalytic water oxidation due to their high catalytic activities, robustness, and stability at neutral $\mathrm{pH}^{[28-30]} \mathrm{A}$ further study by Patzke et al. showed that PBAs can also be used for a light-driven water oxidation process in the presence of $\left[\mathrm{Ru}(\mathrm{bpy})_{3}\right]^{2+}$ as a chromophore. ${ }^{[31]}$ Despite their high turnover frequencies (TOFs), one of the main drawbacks of cyanide-based systems is their low concentration of electroactive cobalt sites. This is because of the relatively large distances between $\mathrm{Co}^{\text {"l }}$ sites (ca. $10 \AA$ ) compared to oxide-based systems (ca. $3 \AA$ ). ${ }^{[28]}$ This problem has recently been overcome by our group with the use of a novel pentacyanoferrate-bound polymer as a precursor of Co-Fe PBAs, which resulted in a dramatic decrease in the crystallinities of PBAs, and thus a significant increase in the surface concentration of Co sites. ${ }^{[32]}$ Galán-Mascarós et al. approached the same problem by using a new synthetic method for the preparation of thin films of PBAs, which 
involves chemical etching of cobalt oxides with a hexacyanoferrate solution to form an in situ PBA film. This novel method led to an impressive improvement in the stability of the electrode and electrocatalytic performance over a wide $\mathrm{pH}$ range. It required a much lower overpotential $(510 \mathrm{mV})$ to obtain a current density of $1 \mathrm{~mA} \mathrm{~cm}^{-2}$. ${ }^{[3]}$ In addition, Fukuzumi et al. investigated the photocatalytic water oxidation performances of a series of Co-Pt PBAs in the presence of the well-defined $\left[\mathrm{Ru}(\mathrm{bpy})_{3}\right]^{2+} / \mathrm{S}_{2} \mathrm{O}_{8}{ }^{2-}$ couple. A systematic study performed with $\left[\mathrm{Co}(\mathrm{CN})_{6}\right]^{3-}$ and $\left[\mathrm{Pt}(\mathrm{CN})_{6}\right]^{4-}$ groups in different stoichiometries clearly showed the number of active sites to be highly dependent on the number of defects. ${ }^{[34,35]}$ Fukuzumi and co-workers also studied the effect of counter cations on the catalytic activity and quantum efficiency displayed by Co-Co PBAs in the photocatalytic water oxidation process, and showed that a quantum efficiency of $200 \%$ could be achieved with such systems incorporating calcium ions as counter cations. ${ }^{[36]}$ The previous studies mentioned above have clearly shown that slight modifications in the structure of PBAs can lead to a significant increase in their catalytic activities. Although previous studies have taken advantage of the rich and well-established cyanide chemistry, to the best of our knowledge, no study has hitherto been performed to investigate the effect of hexacyanometal units on the electronic properties and catalytic performances of electroactive cobalt sites. In the present study, electrocatalytic measurements on a series of cobalt hexacyanometalates (CHCMs) incorporating different $\mathrm{M}(\mathrm{CN})_{6}$ units $\left(\mathrm{M}=\mathrm{Co}^{\prime \prime \prime \prime}, \mathrm{Cr}^{\prime \prime \prime}\right.$, and $\mathrm{Fe}^{\mathrm{II} / \mathrm{II})}$, together with characterization studies, have been performed to investigate the effect of the type and oxidation state of the metal in the $\mathrm{M}(\mathrm{CN})_{6}$ unit on the catalytic activities of PBAs. The effect of hexacyanometal groups on the electronic properties of electroactive cobalt sites has further been examined through electronic structure calculations employing density functional theory (DFT). ${ }^{[37,38]}$

\section{Results and Discussion}

\section{Electrochemistry}

All of the electrochemical experiments were conducted with a PBA-modified fluorine-doped tin oxide (FTO) electrode. Cyclic voltammograms (CVs) of $\mathrm{Co}\left[\mathrm{M}(\mathrm{CN})_{6}\right]\left(\mathrm{M}: \mathrm{Co}^{\prime \prime \prime}, \mathrm{Cr}^{\prime \prime \prime}\right.$, and Fe $\left.{ }^{\mathrm{II} / \mathrm{II}}\right)$ were measured in a phosphate buffer containing $1 \mathrm{M} \mathrm{KNO}$ as the electrolyte in the potential range $0.2-1.7 \mathrm{~V}$ versus $\mathrm{NHE}$ (Figure 1). [Co"-Co"l'] exhibits a quasi-reversible redox couple with an oxidation peak at $1.210 \mathrm{~V}$ and a reduction peak at $1.031 \mathrm{~V}$ versus $\mathrm{NHE}$ that can be assigned to $\mathrm{Co}^{2+} \mathrm{Co}^{3+}$. Similar redox couples are also observed for the other PBAs. Another peak at a more positive potential of around $1.415 \mathrm{~V}$ versus $\mathrm{NHE}$ is observed for $\left[\mathrm{Co}^{\prime \prime}-\mathrm{Co}^{\mathrm{III}}\right]$, which can be assigned to the $\mathrm{Co}^{3+} / \mathrm{Co}^{4+}$ redox process. ${ }^{[39]}$ Tafel plots for each catalyst were obtained by performing chronoamperometry measurements at different applied potentials to further investigate their electrocatalytic performances. A linear trend was obtained between the logarithms of the steady-state current densities and overpotentials in the range $283-483 \mathrm{mV}$, giving Tafel slopes in the range $90-130 \mathrm{mV} \mathrm{dec}^{-1}$ (Figure 2). The Tafel slopes obtained for

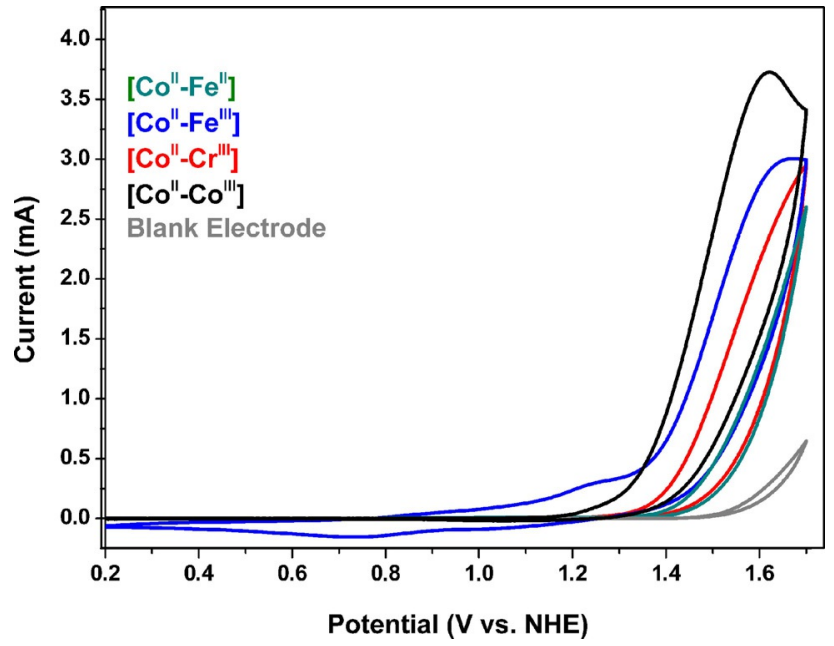

Figure 1. Cyclic voltammograms of PB derivatives ([Co"-Co $\left.{ }^{\prime \prime \prime}\right]$ black, [Co"-Cr"l'] red, [Co"-Fe"'] blue, and [Co"-Fe"] green lines) in $50 \mathrm{~mm} \mathrm{KPi}$ electrolyte at $\mathrm{pH} 7$ at $50 \mathrm{mV} \mathrm{s}^{-1}$ sweep rate. The gray line indicates the electrochemical response of the blank electrode.

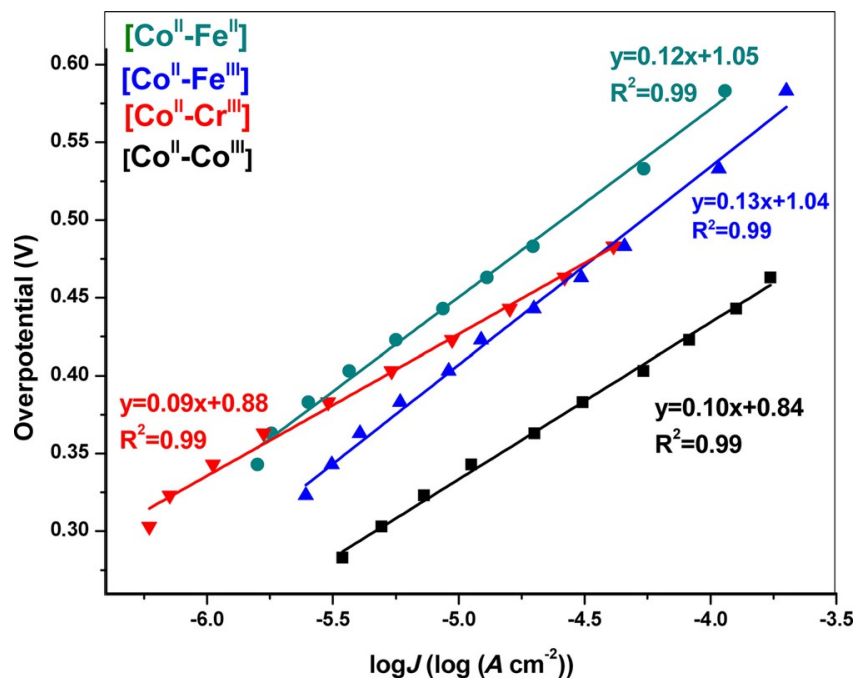

Figure 2. Tafel plots for PB derivatives from 1.1 to $1.4 \mathrm{~V}$ versus NHE recorded in a $50 \mathrm{~mm} \mathrm{KPi} \mathrm{buffer} \mathrm{at} \mathrm{pH}$ 7.0.

[Co"-Fe"] and [Co"-Fe"l'] were slightly higher than those reported previously by Galan-Mascarós et al. ${ }^{[28,33]}$ The difference can mainly be attributed to different preparation methods, since PBA-modified electrodes prepared by an in situ method exhibit lower Tafel slopes (ca. $90 \mathrm{mV} \mathrm{dec}^{-1}$ ) compared to those prepared by drop-casting. ${ }^{[26,32]}$

A similarity of Tafel slopes indicates similar OER mechanisms. According to chronoamperometric measurements, onset overpotentials of 283,303,323, and $343 \mathrm{mV}$ were obtained for $\left[\mathrm{Co}^{\prime \prime}-\mathrm{Co}^{\prime \prime \prime}\right],\left[\mathrm{Co}^{\prime \prime}-\mathrm{Cr}^{\prime \prime \prime}\right],\left[\mathrm{Co}^{\prime \prime}-\mathrm{Fe}{ }^{\prime \prime \prime}\right]$, and $\left[\mathrm{Co}^{\prime \prime}-\mathrm{Fe}^{\prime \prime}\right]$, respectively, which are consistent with those of cyclic voltammetric studies (Figure S1). The surface coverage of electroactive $\mathrm{Co}^{2+}$ species on an FTO electrode, that is, the surface concentration, was determined by recording CVs at different scan rates (25$225 \mathrm{mV} \mathrm{s}^{-1}$ ) in the range $0.8-1.6 \mathrm{~V}$. Surface concentrations of the derivatives were estimated to be in the range 2- 
$5 \mathrm{nmol} \mathrm{cm}{ }^{-2}$, in good agreement with the results of previously reported studies (Figure S2). ${ }^{[28,32]}$

Surface concentration was used to assess turnover frequencies (TOFs) of the PBAs. TOFs at an overpotential of $400 \mathrm{mV}$ were evaluated as $5.0 \times 10^{-2} \mathrm{~s}^{-1}, 3.0 \times 10^{-3} \mathrm{~s}^{-1}, 4.4 \times 10^{-3} \mathrm{~s}^{-1}$, and $5.0 \times 10^{-3} \mathrm{~s}^{-1}$ for [Co"-Co"l'], [Co"l-Fe"], [Co" $\left.-\mathrm{Fe}^{\prime \prime \prime}\right]$, and [Co"l$\left.\mathrm{Cr}^{\prime \prime \prime}\right]$, respectively (Figure S3). Comparison of the TOFs shows that the available $\mathrm{Co}^{\text {"I }}$ sites in [Co"-Co"l'] exhibit the highest catalytic activity. Chronopotentiometry (CP) was performed to determine the overpotential required to obtain a current density of $1 \mathrm{mAcm}^{-2}$ during a $2 \mathrm{~h}$ experiment. The overpotential for [Co"l-Co"l'] slightly decreased at first and then maintained a constant level, whereas those for the other PBAs gradually increased until stabilization. The overpotentials observed at $1 \mathrm{mAcm}^{-2}$ are slightly higher than those extracted from the Tafel slopes due to the formation of $\mathrm{O}_{2}$ bubbles on the electrode surface during the measurement. CP studies showed that [Co"-Co"I'] exhibited the lowest overpotential, and $\eta_{1 \mathrm{~mA}}$ was determined as 531, 578, 661, and $692 \mathrm{mV}$ for [Co"-Co"'], [Co"$\left.\mathrm{Cr}^{\prime \prime \prime}\right]$, [Co $\left.-\mathrm{Ce}^{\prime \prime \prime}\right]$, and [Co"$\left.-\mathrm{Ce}^{\prime \prime}\right]$, respectively (Figure 3, Table 1).

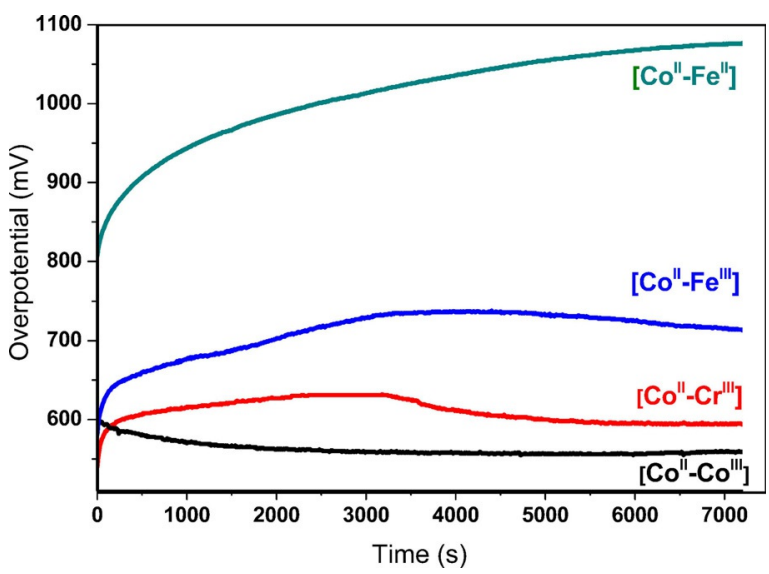

Figure 3. Chronopotentiometry measurements of $\mathrm{PB}$ derivatives at $1 \mathrm{~mA} \mathrm{~cm}^{-2}$ in a $50 \mathrm{~mm}$ KPi buffer at $\mathrm{pH} 7.0$.

Long-term chronoamperometric studies at an applied potential of $1.4 \mathrm{~V}$ versus NHE were performed to investigate the stability of the PBA-modified electrodes. The current density for each catalyst decreased until it reached a constant value, as previously reported by our group and by Galán-Mascarós et al. ${ }^{[28,32]}$

The same trend was observed over for four repeated cycles, and the close similarity of cyclic voltammetric profiles obtained after each cycle indicated that the catalysts retained their structure even during long-term catalytic processes (Figure S4). An interesting anomaly was observed for [Co"l-Cr"l'], for which a decrease in current density was observed as usual, but this was followed by an abrupt increase after around $10 \mathrm{~h}$. Comparison of the CVs obtained before and after a $24 \mathrm{~h}$ electrolysis experiment indicated a significant decrease in the onset overpotential and catalytic current density, which could be attributed to the decomposition of [Co" $\left.-\mathrm{Cr}^{\prime \prime \prime}\right]$ to a more catalytically active species. Our characterization studies, which will be discussed in the following section, also suggest that decomposition only occurs during long-term electrolysis studies (longer than $10 \mathrm{~h}$ ). Furthermore, a similar electrolysis study, employing an $\mathrm{O}_{2}$ probe, was performed on $\left[\mathrm{Co}^{\prime \prime}-\mathrm{Co}^{\mathrm{II}}\right]$ to investigate the origin of the current density and Faradaic efficiency. The perfect match between the theoretical yield obtained from chronocoulometry measurement and the experimental yield obtained by means of an $\mathrm{O}_{2}$ probe indicated that the sole origin of the current density was catalytic water oxidation with the evolution of $\mathrm{O}_{2}$, and that there were no competing redox reactions (Figure S5).

\section{Characterization studies}

All samples were isostructural with the Prussian Blue crystal structure, adopting a face-centered cubic (fcc) form, with space group $\mathrm{Fm} 3 \mathrm{~m}$, as confirmed by powder XRD studies. The characteristic $2 \theta$ peaks for Prussian Blue were observed for all of the materials (Figure S6), and the lattice parameter was determined to be around $10 \AA$ for each derivative (Table S1). XRD analysis in grazing incidence mode was also performed on the catalysts deposited on FTO before (pristine) and after (post-catalytic) the electrocatalytic studies, to investigate their structural stability during electrocatalysis. No additional peaks were observed in the XRD patterns of the post-catalytic samples, and the peaks corresponding to the Prussian Blue-type structure remained, confirming the stability of the catalysts (Figure 4). The atomic ratio of metals in each compound was determined by EDX analysis (Table S2). The following molecular formulae were obtained, based on stoichiometric ratio of metals: $\mathrm{K}_{0.76} \mathrm{Co}_{2.62}\left[\mathrm{Co}(\mathrm{CN})_{6}\right]_{2}, \quad \mathrm{~K}_{0.82} \mathrm{CO}_{2.59}\left[\mathrm{Cr}^{\prime \prime \prime}(\mathrm{CN})_{6}\right]_{2}, \quad \mathrm{~K}_{0.62} \mathrm{Co}_{2.69}\left[\mathrm{Fe}^{\prime \prime \prime \prime}(\mathrm{CN})_{6}\right]_{2}$, and $\mathrm{K}_{1.40} \mathrm{CO}_{3.30}\left[\mathrm{Fe}{ }^{\prime \prime}(\mathrm{CN})_{6}\right]_{2}$ for [Co"-Co"l'], [Co"l-Cr"l'], [Co"l-Fe"ll'], and [Co"l-Fe"], respectively. Each compound has a similar potassium content in the range $0.6-0.8$, which results in an average of about 4.5 CN groups per Co" site. The coordination spheres of the Co" sites are completed by water molecules, which play an active role in water oxidation (Figure S7).

Infrared studies showed that the PBAs exhibited the characteristic bands associated with Prussian Blue-type systems: a) a

\begin{tabular}{|c|c|c|c|c|c|c|c|c|}
\hline Compound & $\begin{array}{l}\mathrm{Co}^{2+} \beta^{3+} \\
{[\mathrm{V}]}\end{array}$ & $\begin{array}{l}v(\mathrm{CN}) \\
{\left[\mathrm{cm}^{-1}\right]}\end{array}$ & $\begin{array}{l}\text { TOF } \\
{[\eta=400 \mathrm{mV}]}\end{array}$ & $\begin{array}{l}\text { Surface concentration } \\
{\left[\mathrm{nmol} \mathrm{cm}{ }^{-2}\right]}\end{array}$ & $\begin{array}{l}\eta_{1 \mathrm{~mA}} \text { from } \\
\text { Tafel plot }[\mathrm{mV}]\end{array}$ & $\begin{array}{l}\text { Tafel Slope } \\
{\left[\mathrm{mV} \mathrm{dec}^{-1}\right]}\end{array}$ & $\begin{array}{l}\eta_{1 \mathrm{~mA}} \text { from } \\
\mathrm{CP}[\mathrm{mV}]\end{array}$ & $\begin{array}{l}\eta_{\text {onset }} \\
{[\mathrm{CV}]}\end{array}$ \\
\hline [Co"-Co"l'] & 1.010 & 2176 & $5.0 \times 10^{-2}$ & 4.11 & 531 & 99 & 565 & 283 \\
\hline [Co"-Cr'll'] & 1.084 & 2173 & $5.0 \times 10^{-3}$ & 3.90 & 578 & 96 & 598 & 303 \\
\hline$\left[\mathrm{CO}^{\prime \prime}-\mathrm{Fe}^{\prime \prime \prime}\right]$ & 1.084 & 2120 & $4.4 \times 10^{-3}$ & 5.48 & 661 & 127 & 717 & 323 \\
\hline$\left[\mathrm{Co}-\mathrm{Fe}^{\prime \prime}\right]$ & 0.995 & 2072 & $3.0 \times 10^{-3}$ & 2.00 & 692 & 121 & 1079 & 343 \\
\hline
\end{tabular}




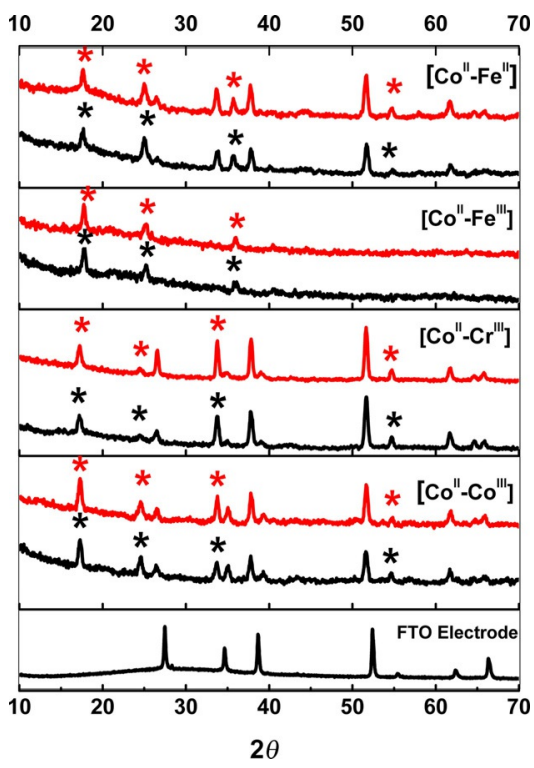

Figure 4. GI-XRD patterns of PB derivatives for pristine (black lines) and post-catalytic samples (red lines). Peaks attributable to the FTO electrode are marked with triangles $(\mathbf{\Delta})$ and those attributable to Prussian Blue are marked with asterisks $\left({ }^{*}\right)$

sharp band at around $1610 \mathrm{~cm}^{-1}$ and a broad feature at 3200$3500 \mathrm{~cm}^{-1}$, which correspond to $\mathrm{HOH}$ bending and $\mathrm{OH}$ stretching, respectively; b) a sharp peak at around $490-590 \mathrm{~cm}^{-1}$ due to $\mathrm{M}-\mathrm{C}$ stretching; and C) a sharp peak at around 2120$2180 \mathrm{~cm}^{-1}$ attributable to CN stretching (Table S3). PBAs exhibit higher $\mathrm{CN}$ stretching frequencies compared to their hexacyanometal precursors, which confirms the binding of nitrogen atoms of cyanide to $\mathrm{Co}^{11}$ sites $^{[28,40]}$ (Figure S8). Infrared analysis was also performed on the post-catalytic samples. The close similarity between the cyanide stretching IR bands of the pristine and post-catalytic samples suggests that the $\mathrm{M}-\mathrm{CN}-\mathrm{Co}^{\prime \prime}-$ type coordination mode of the catalysts is preserved during electrolysis (Figure S9). A slight shift to higher frequencies in the case of post-catalytic [Co"-Fe"], which was also observed in previous studies, can be attributed to partial oxidation of iron ions from +2 to +3 during the electrocatalysis.

XPS studies also confirmed the remarkable stability of the PBA electrocatalysts. In order to investigate the oxidation state of electroactive $\mathrm{Co}^{\text {"l }}$ sites in the pristine and post-catalytic electrodes, the Co2p signal was examined in the binding energy region $810-775 \mathrm{eV}$. In previous studies, the binding energies of $\mathrm{Co}_{2} \mathrm{p}_{3 / 2}$ and $\mathrm{Co} 2 \mathrm{p}_{1 / 2}$ signals for Co" salts have been reported as 782.28 and $798.38 \mathrm{eV}$, respectively. For the pristine samples, the $C_{0} 2 p_{3 / 2}$ and $C 02 p_{1 / 2}$ signals were observed in the same range. The similarity between the binding energies of the Co2p signals obtained for pristine PBAs and previously reported Co" salts suggests that the oxidation state of electroactive Co atoms is +2 (Figure 5). No significant changes in the Co2 $\mathrm{p}_{3 /}$ ${ }_{2}$ and $\mathrm{CO}_{2} \mathrm{p}_{1 / 2}$ signals were observed in the post-catalytic samples, indicating the stability of the Co" sites.

In addition to Co2p, the $01 \mathrm{~s}$ signals were also examined for both the pristine and post-catalytic samples (Figure S10). An O1s signal with a binding energy higher than $530 \mathrm{eV}$ indicated

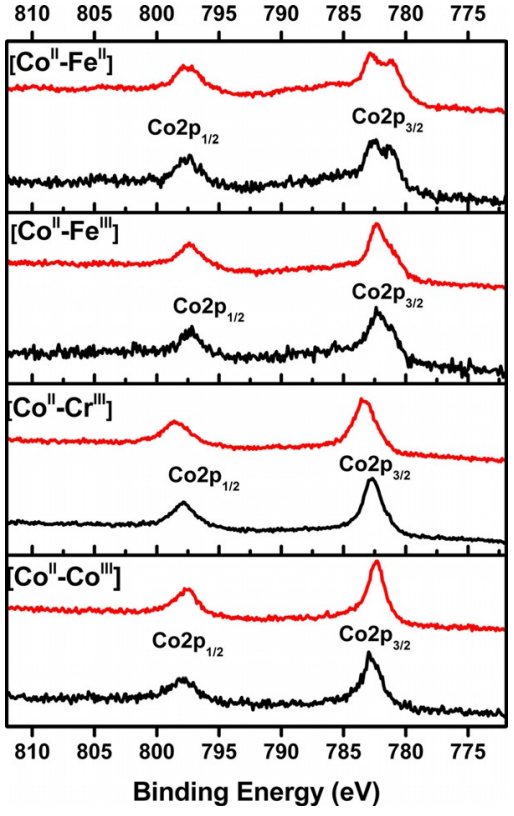

Figure 5. XPS of Co2p region for pristine (black lines) and post-catalytic (red lines) samples of PB derivatives.

an absence of any cobalt oxide species before and after electrochemical experiments, even for [ $\left.\mathrm{CO}^{\prime \prime}-\mathrm{Cr}^{\prime \prime \prime}\right]$. The observed values are displayed in Table S4. A moderate broadening of the O1s signal is evident in the post-catalytic samples, indicating a partial and reversible oxidation of electroactive Co" sites.

\section{Mechanism of catalytic water oxidation}

The $\mathrm{CN}$ stretching vibration may be considered as a fingerprint for cyanide-based coordination compounds. A comparison of shifts in the cyanide stretch can be used not only to confirm the bridging mode of the cyanide group, but also to evaluate the oxidation states, and hence the electron densities, of the metal ions. Considering that the cyanide stretching vibration shifts to higher frequencies as the oxidation state of the metal increases, a direct correlation can be established between the shift of the cyanide stretch and the electron deficiency of Co" centers. Comparison of the cyanide stretches implies that the electron densities at the Co" sites in our Prussian blue analogues can be ordered as: [Co" $\left.-\mathrm{CO}^{\prime \prime \prime \prime}\right] \approx\left[\mathrm{Co}^{\prime \prime}-\mathrm{Cr}^{\prime \prime \prime}\right]<\left[\mathrm{Co}^{\prime \prime}-\mathrm{Fe}^{\prime \prime \prime \prime}\right]<$ [Co"-Fe"] (Figure 6). This result is also in good agreement with the binding energies of the Co2p orbitals obtained by XPS studies. The ordering of the $\mathrm{Co} 2 \mathrm{p}_{3 / 2}$ peaks is [Co" $\left.-\mathrm{Co}^{\prime \prime \prime}\right]>[\mathrm{Co} "-$ $\left.\mathrm{Cr}^{\prime \prime \prime}\right]>\left[\mathrm{Co}^{\prime \prime}-\mathrm{Fe}^{\prime \prime \prime \prime}\right]>\left[\mathrm{Co}^{\prime \prime}-\mathrm{Fe}^{\prime \prime}\right]$, implying that the Co" sites in the [Co"l-Co"l'] analogue have the lowest electron densities in the series. The evaluation of electron densities can provide insight into the rate-determining step (r.d.s.) in water oxidation catalysis. Two steps have generally been reported as competing as the r.d.s. in water oxidation process: i) $\mathrm{Co}{ }^{\mathrm{III}}-\mathrm{OH} / \mathrm{Co}^{\mathrm{IV}}-\mathrm{O}$ (oxo) or

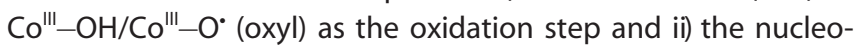
philic attack of water at the electrophilic oxygen atom of oxo/ oxyl species, resulting in $\mathrm{O}-\mathrm{O}$ bond formation. An increase in the electron density at the Co" site facilitates the former step, 


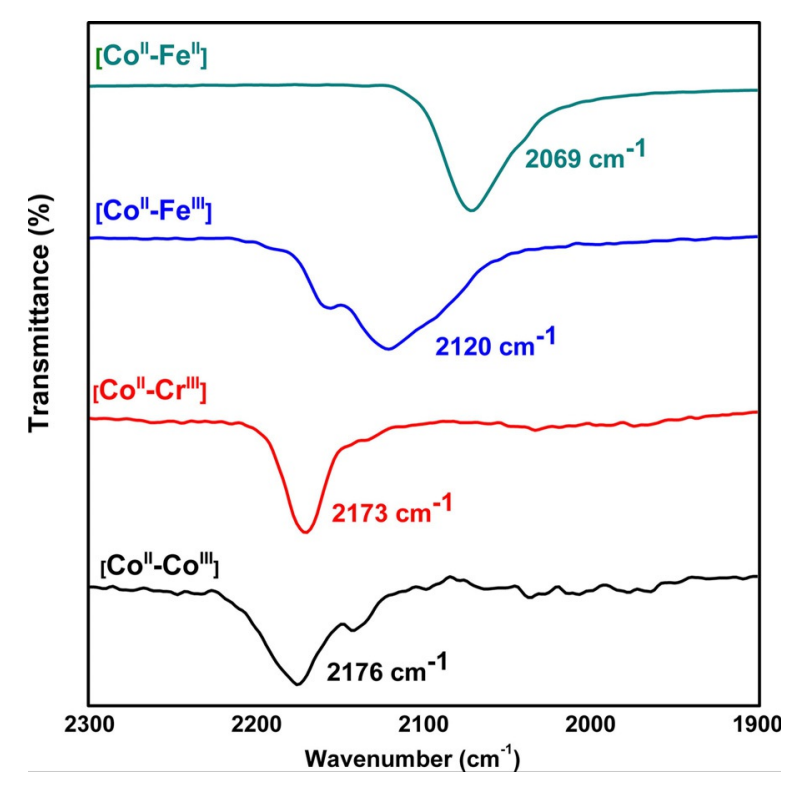

Figure 6. FTIR spectra of PB derivatives showing cyanide stretches.

while decreasing the electrophilic nature of the oxo intermediate and thus impeding the latter. The above discussion on the electron densities of $\mathrm{Co}^{\prime \prime}$ sites in PBAs and their electrocatalytic performances clearly shows that [CO $\left.\mathrm{CO}^{\prime \prime}-\mathrm{Co}^{\prime \prime \prime}\right]$ stands out as the most efficient catalyst among the studied PBAs, which has Co" sites with the lowest electron density. This correlation implies that nucleophilic attack of water on the oxo/oxyl intermediate is the r.d.s. of the water oxidation process for PBAs. It should be noted that the electronic properties of the catalysts will differ when a potential is applied. Catalytically active cobalt ions will be in their higher oxidation states, particularly when the applied potential is above $1 \mathrm{~V}$ versus NHE. Nevertheless, the difference in the electron densities of the cobalt ions should be preserved, given that the structural integrity of the cyanide framework is preserved and that the metal ion in the $\mathrm{M}(\mathrm{CN})_{6}$ building block is not oxidized. While this assumption may be valid for hexacyanometal groups that contain metal ions in their $3+$ oxidation state, the $\mathrm{Fe}^{2+}$ ion in the $\left[\mathrm{Fe}(\mathrm{CN})_{6}\right]^{4-}$ group would be expected to be oxidized when a potential above $1 \mathrm{~V}$ is applied. ${ }^{[41]}$ The oxidation of all $\mathrm{Fe}^{2+}$ ions is, however, a kinetically demanding process, since it requires more potassium ions to be transported from the framework to the electrolyte to maintain charge neutrality and, more importantly, there are insufficient potassium ions to produce a fully oxidized [Co $\left.{ }^{\prime \prime \prime}-\mathrm{Fe}^{\mathrm{III}}\right]$ system. Therefore, the catalytically active species in [Co"-Fe"] contains a mixture of Fe ions with oxidation states of $2+$ and $3+$. The difference in the curvatures of the bands assigned to the $\mathrm{Fe}^{2+/ 3+}$ and $\mathrm{Co}^{2+/ 3+}$ redox processes for [Co"l-Fe"] and [Co"-Fe"l'] also indicates different kinetics for these two analogues (Figure S11). The lower surface concentration and turnover frequency obtained for [Co"-Fe"] may thus be attributed to differences in the kinetics of its electron transfer and its electronic properties.

A further analysis of the mechanism was made based on the Pourbaix diagram (Figure 7), which was obtained by recording

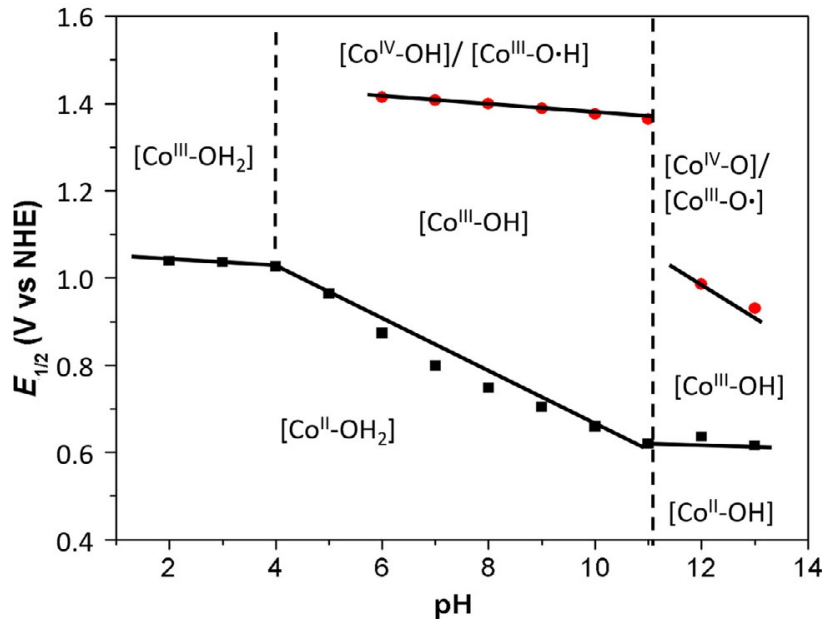

Figure 7. Pourbaix diagram of $\left[\mathrm{CO}^{\prime \prime}-\mathrm{Co}^{\prime \prime \prime}\right]$ in $\mathrm{KPi}$ buffer over the range $\mathrm{pH} 2-$ 13. Cyclic voltammograms recorded at these $\mathrm{pH}$ values are shown in Figure S10.

CVs for [Co"l-Coll'] at different $\mathrm{pH}$ values (Figure S12). The diagram shows that $\mathrm{Co}^{2+} / \mathrm{Co}^{3+}$ redox process is $\mathrm{pH}$-dependent in the range $\mathrm{pH} 4-10$ with a slope of $64 \mathrm{mV} \log \left[\mathrm{H}^{+}\right]^{-1}$, which refers to a $1 \mathrm{H}^{+}-1 \mathrm{e}^{-}$process.

Interestingly, the half-potential for the second redox step is preserved, regardless of $\mathrm{pH}(<11)$, which indicates that a hydroxyl group is coordinated to the catalytically active $\mathrm{Co}^{\mathrm{IV}}$-oxo/ $\mathrm{Co}$ III-oxyl intermediate under neutral conditions. An $\left[\mathrm{N}_{5} \mathrm{CO}^{\mathrm{IV}}-\mathrm{OH}\right]$ intermediate could be deprotonated in a subsequent step to form a cobalt oxo/oxyl complex, and then undergo nucleophilic attack of water to form a peroxo intermediate, which is one of the essential steps for $\mathrm{O}-\mathrm{O}$ bond formation. A slightly different mechanism to that commonly accepted for oxides is thus proposed for PBAs. The presence of additional peaks in the CVs obtained at above $\mathrm{pH} 11$ suggests that water oxidation proceeds with a different mechanism under basic conditions.

\section{Electronic structure calculations}

In order to gain insight into the different performances of the PB analogues studied in this work, electronic structure calculations were performed with $\mathrm{DFT}^{[37,38]}$ (see the $\mathrm{SI}$ for details). It is critical to understand the reason for the rate enhancement along the $\mathrm{Fe}^{\prime \prime}, \mathrm{Fe}^{\mathrm{III}}, \mathrm{Cr}^{\mathrm{III}}$, and $\mathrm{Co}^{\mathrm{III}}$ cationic series used as the second metal separated from the catalytically active Co site by a cyanide bridge.

Oxidation of water would require the proton coupled electron transfer (PCET) steps to afford the formal $\mathrm{CO}^{\mathrm{IV}}{ }_{-} \mathrm{oxo} / \mathrm{Co}^{\mathrm{III}}-\mathrm{O}^{\circ}$ moiety from the substrate-bound aqua center with $\mathrm{a}+2$ formal charge, that is, $\mathrm{Co}^{\prime \prime}\left(\mathrm{OH}_{2}\right) \rightarrow \mathrm{Co}{ }^{\prime \prime \prime}(\mathrm{OH}) \rightarrow \mathrm{Co}^{\mathrm{IV}}(\mathrm{O}) / \mathrm{Co}^{\text {III-}}-\left(\mathrm{O}^{*}\right)$. Once $\mathrm{Co}^{\mathrm{IV}}(\mathrm{O})$ is accessed, it is attacked by water to afford the $\mathrm{O}-\mathrm{O}$ bond. This picture is consistent with the existing mechanistic data in the literature. ${ }^{[39,42]}$ Therefore, the structural and electronic properties of the $\mathrm{CO}^{\mathrm{IV}}(\mathrm{O}) / \mathrm{CO}^{\mathrm{III}}-\left(\mathrm{O}^{\circ}\right)$ center are the main focus of our quantum chemical calculations. It is important to note that there are no restrictions on the distribution of electrons in our calculations, and thus formal assignments 
of $\mathrm{Co}^{\mathrm{IV}}(\mathrm{O})$ or $\mathrm{Co}^{\mathrm{III}}-\left(\mathrm{O}^{\circ}\right)$ for the Co center are less comprehensive levels of describing the $\mathrm{Co}-\mathrm{O}$ bond compared to the completely delocalized (canonical) orbital picture given by quantum chemical calculations.

DFT calculations suggest that the catalytically active Co-O site is a local quartet and hence hosts three unpaired electrons. Depending on the nature of the neighboring metal in a strong field environment, either one or zero electrons contribute to the total spin when a bimetallic model is considered, as given in Table S5. The local quartet spin arrangement of the $\mathrm{Co}^{\text {IV }}$ center is also verified by spin density analysis, as given in Table 2. Interestingly, the reactive $\mathrm{Co}^{\mathrm{IV}}$ center has a high degree of radical character distributed over the $\mathrm{Co}-\mathrm{O}$ bond. Such electronic structure fingerprints of high-valent Co moieties were recently shown to be related to reactivity, ${ }_{1}^{[43]}$ where an

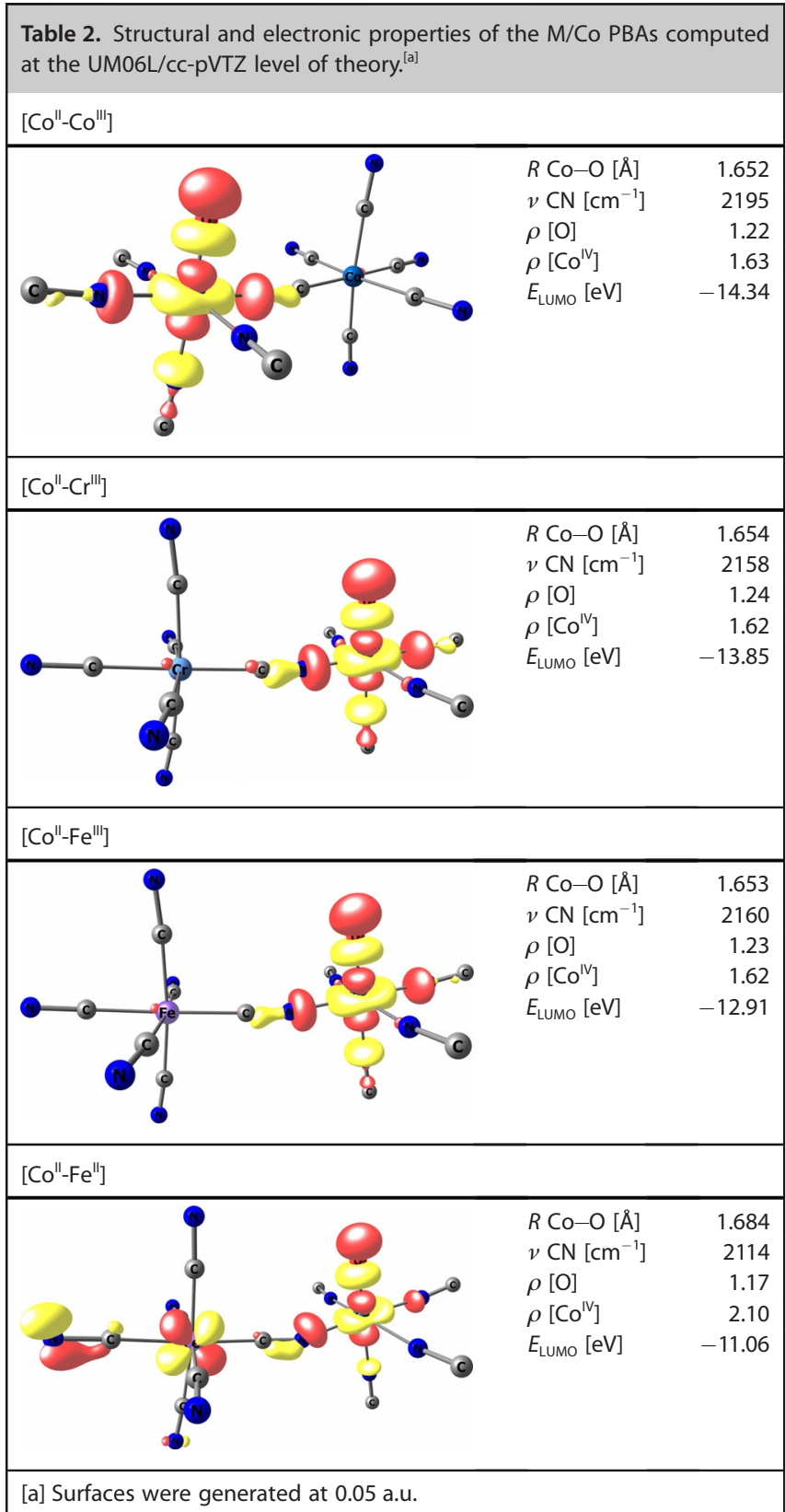

apparent $\mathrm{Co}^{\mathrm{IV}}=$ oxo species having a mixed electronic structure of the oxyl/oxo type was reported. In that work, one of us (Y.D.) showed that, similarly to the case reported here, the oxowall ${ }^{[43]}$ was indeed not broken, and the local quartet spin arrangement, delocalized along the $\mathrm{Co}-\mathrm{O}$ bond, showed substantial radical character on oxygen. Overall, a more appropriate electronic structure assignment for the in situ generated, catalytically competent, $\mathrm{O}-\mathrm{O}$ bond-forming species is a mixed Co-oxo/oxyl.

$\mathrm{CN}$ stretching frequencies $(v(\mathrm{CN}))$ and molecular orbitals were investigated to elucidate the molecular basis for the catalytic activity (Table 2 ).

The calculated trend in $v(\mathrm{CN})$ is in good agreement with the experimental results, and shows the flow of electron density from the Co site. More importantly, the critical O-O bondforming step can be readily understood by analyzing the attack of water on the Co-O center. The oxygen lone pairs borne by water are seeking vacant orbitals on the $\mathrm{Co}-\mathrm{O}$ center, for which the best candidate is the LUMO. As shown in Table S5, the $\sigma^{*}$ MO generated from Co_d and O_p contributions is obtained at lower energies ( $E_{\text {LUMO }}$ in Table 2 ) through the $\mathrm{Fe}^{\prime \prime}, \mathrm{Fe}^{\mathrm{III}}, \mathrm{Cr}^{\mathrm{III}}$, and $\mathrm{Co}^{\prime \prime \prime}$ sites. Thus, the electron affinity of the $\mathrm{Co}^{\mathrm{IV}}-\mathrm{O}$ center is increased; the attack of water becomes more facile, and this accounts for the lower overpotentials measured in our electrochemical experiments. Our quantum chemical calculations thus show that the reactive Co-oxo/oxyl center possesses a local quartet spin arrangement. Two of the three quartet spin electrons are distributed over Co and one over oxygen; however, all three electrons can be better described as sharing Co_d and O_p orbitals through the Co-O bond. The reactivity correlates with attaining the LUMO, to be attacked by incoming water, at lower energies, as summarized in Figure 8. Note that this truncated quantum chemical model may not capture all of the structural features of the PB surface, but it is a good compromise between accuracy and cost. Moreover, with the assistance of the experimental data, the electronic structure of the active species could be assigned as $\mathrm{Co}^{\mathrm{IV}}(\mathrm{O}) / \mathrm{Co}^{\mathrm{III}}-\left(\mathrm{O}^{\circ}\right)$, and hence the model chemistry is useful.

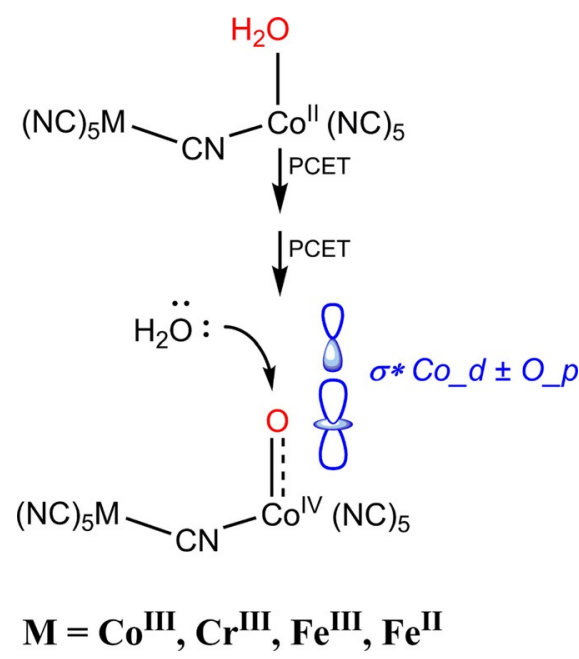

Figure 8. $\mathrm{O}-\mathrm{O}$ bond formation at the $\mathrm{CO}^{\mathrm{IV}}-\mathrm{O}$ center. 


\section{Conclusions}

Previous electrochemical studies on Prussian Blue analogues have shown that having a cobalt site coordinated to nitrogen atoms of a cyanide bridging group is essential to obtain efficient PBA electrocatalysts for water oxidation. Here, members of a series of cobalt hexacyanometalates with the general formula $\mathrm{K}_{a} \mathrm{Co}_{b}\left[\mathrm{M}(\mathrm{CN})_{6}\right]\left(\mathrm{M}: \mathrm{Co}^{\mathrm{III}}, \mathrm{Cr}^{\mathrm{III}}\right.$, and $\left.\mathrm{Fe}^{\mathrm{II} / \mathrm{II}}\right)$ have been prepared to investigate the effect of the hexacyanometal groups on the electrocatalytic activity of CHCMs. Tafel analysis and chronoamperometry experiments have revealed that $\left[\mathrm{Co}^{\mathrm{II}}-\mathrm{Co}^{\mathrm{III}}\right]$ serves as the most efficient electrocatalyst for water oxidation among the studied CHCMs. Infrared and XPS studies have indicated that it has the Co" center with the lowest electron density, which has also been confirmed by DFT studies.

Overall, experimental and computational studies have led to the following conclusions:

i) The electron density of $\mathrm{Co}^{\prime \prime}$ is a decisive electronic criterion for achieving efficient water oxidation electrocatalysis, and this parameter may be tuned by changing the type of hexacyanometal group.

ii) The electron density of Co" can be reduced by increasing the oxidation state of the metal ion of the $\left[M(C N)_{6}\right]^{n-}$ group.

iii) Electrophilicity of the Co $\mathrm{CO}^{\mathrm{V}}-\mathrm{O}$ center can be probed by molecular orbital analysis, and this might be a useful tool for the realization of new PBAs bearing reactive Co species as potent WOCs.

iv) Nucleophilic attack of water on the cobalt-oxo intermediate should be the rate-determining step for water oxidation catalysis with PBAs.

v) Theoretical calculations show that the $\mathrm{O}-\mathrm{O}$ bond-forming species has mixed Co-oxo/oxyl character.

In conclusion, the following mechanism may be proposed, based on the experimental and computational studies (Figure 9). This study has shown that electronic properties, and hence the electrocatalytic activity of the catalytically active cobalt site, can be easily tuned through the versatile chemistry of PBAs, and neighboring metal ions should also be considered as an important parameter to evaluate the catalytic activities of water oxidation electrocatalysts. Detailed electronic structure calculations, employing multi-reference techniques, on various $\mathrm{Co}-\mathrm{O}$ systems are underway aimed at corroborating the nature of the $\mathrm{Co}^{\mathrm{IV}}-\mathrm{O}$ bonding and reactivity.

\section{Experimental Section}

\section{Chemicals and solutions}

Potassium hexacyanocobaltate $\mathrm{K}_{3}\left[\mathrm{Co}(\mathrm{CN})_{6}\right](>97.0 \%)$, cobalt(II) chloride hexahydrate $\mathrm{CoCl}_{2} \cdot 6 \mathrm{H}_{2} \mathrm{O}(98.0 \%)$, potassium hexacyanochromate $\mathrm{K}_{3}\left[\mathrm{Cr}(\mathrm{CN})_{6}\right] \quad(99.99 \%)$, potassium hexacyanoferrate $\mathrm{K}_{3}\left[\mathrm{Fe}(\mathrm{CN})_{6}\right](>97.0 \%)$, and potassium hexacyanoferrate trihydrate $\mathrm{K}_{3}\left[\mathrm{Fe}(\mathrm{CN})_{6}\right] \cdot 3 \mathrm{H}_{2} \mathrm{O}(98.5-102 \%)$ were all obtained from Sigma-Aldrich. All the solutions were prepared with Millipore Milli-Q deionized water with a resistivity of $18.2 \mathrm{~m} \Omega \mathrm{cm}$.

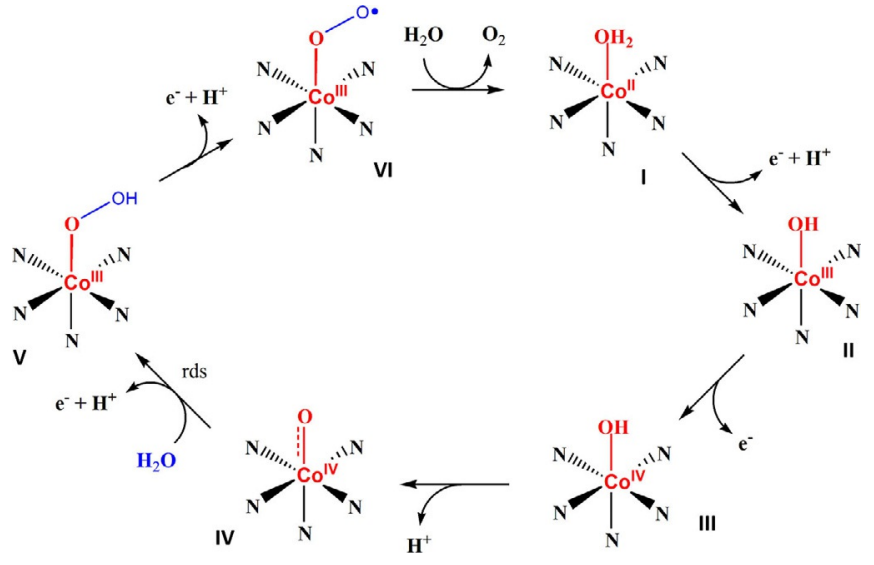

Figure 9. Proposed mechanism for water oxidation process by PBAs.

$\mathrm{K}_{a} \mathrm{Co}_{b}\left[\mathrm{M}(\mathrm{CN})_{6}\right] \cdot \mathrm{H}_{2} \mathrm{O}\left(\mathrm{M}=\mathrm{Fe}^{\prime \prime \prime}, \mathrm{Fe}^{\prime \prime \prime \prime}, \mathrm{Co}^{\prime \prime \prime \prime}\right.$, and $\left.\mathrm{Cr}^{\prime \prime \prime}\right)$ are abbreviated throughout as [Co"-Fe"], [Co"-Fe" $],\left[\mathrm{Co}^{\prime \prime}-\mathrm{Co}^{\prime \prime \prime}\right]$, and [Co" $\left.-\mathrm{Cr}^{\prime \prime \prime}\right]$. In the case of $\left[\mathrm{Co}^{\prime \prime}-\mathrm{Co}^{\prime \prime \prime}\right]$, an aqueous solution of $\mathrm{CoCl}_{2} \cdot 6 \mathrm{H}_{2} \mathrm{O}(0.15 \mathrm{M}$, $20 \mathrm{~mL}$ ) was added dropwise to an aqueous solution of $\mathrm{K}_{3}\left[\mathrm{Co}(\mathrm{CN})_{6}\right]$ $(0.10 \mathrm{M}, 20 \mathrm{~mL})$ at room temperature. The mixture was stirred for $1 \mathrm{~h}$ and then left to stand overnight for precipitation. It was then filtered by vacuum suction, and the residue was washed with copious amounts of water to obtain a pink powder. The powder was then dried in a desiccator. The same procedure was applied for [Co"-Fe"] (dark-blue), [Co"-Fe"'] (dark-brown), and [Co"-Cr"'] (paleyellow).

\section{Preparation PBA-modified FTO electrodes}

FTO electrodes were procured from Sigma-Aldrich (with about $80 \%$ transmittance, $2 \mathrm{~mm}$ with a surface resistance of $7 \Omega \mathrm{sq}^{-1}, 1 \times$ $2 \mathrm{~cm}$ ). The electrodes were washed by sonication for $10 \mathrm{~min}$ each in basic soapy solution, deionized water, and isopropanol, respectively. They were then annealed at $400^{\circ} \mathrm{C}$ for $30 \mathrm{~min}$. Catalystmodified electrodes were prepared by a drop-casting method. A mixture of PBA catalyst $(5 \mathrm{mg})$, DMF $(500 \mu \mathrm{L})$, water $(500 \mu \mathrm{L})$, and Nafion ${ }^{\circ}$ solution $(100 \mu \mathrm{L})$ was sonicated for $30 \mathrm{~min}$ to prepare a stable suspension, $50 \mu \mathrm{L}$ of which was removed and dropped onto an FTO electrode to cover $1 \mathrm{~cm}^{2}$. The electrodes were dried at room temperature for $10 \mathrm{~min}$ and then at $80^{\circ} \mathrm{C}$ in an oven for $10 \mathrm{~min}$. They were left in a desiccator prior to use for electrochemical experiments and characterization.

\section{Electrochemical measurements}

A Gamry Instruments Interface 1000 potentiostat/galvanostat was used for electrochemical measurements. A conventional three-electrode cell was used, with $\mathrm{Ag} / \mathrm{AgCl}(3.5 \mathrm{M} \mathrm{KCl})$ as the reference electrode, FTO as the working electrode, and a Pt wire as the counter electrode. A YSI 5100 dissolved oxygen sensing electrode instrument equipped with a dissolved oxygen field probe was used to determine oxygen evolution. Phosphate buffer solution (KPi) was prepared by using $\mathrm{KH}_{2} \mathrm{PO}_{4}$ and $\mathrm{K}_{2} \mathrm{HPO}_{4}$, and the $\mathrm{pH}$ of the solution was adjusted by adding $\mathrm{H}_{3} \mathrm{PO}_{4}$ or $\mathrm{KOH}$. Bulk water electrolysis was performed in a two-compartment cell separated by a glass frit. The electrolysis and steady-state chronoamperometry experiments were performed in $\mathrm{KPi}$ buffer solution containing $1 \mathrm{M} \mathrm{KNO}_{3}$ as a supporting electrolyte. A Mettler Toledo S220 SevenCompact ${ }^{\mathrm{TM}} \mathrm{pH} /$ ion $\mathrm{pH}$ meter was used to determine the $\mathrm{pH}$ of buffer solutions. All of the electrochemical experiments were performed at room temperature and under $\mathrm{N}_{2}$ atmosphere. 


\section{Physical measurements}

XRD patterns were measured by means of a PanAnalytical X'PertPro multipurpose $\mathrm{X}$-ray diffractometer (MPD) employing $\mathrm{Cu}_{k \alpha}$ radiation $(\lambda=1.5418 \AA$ ). GI-XRD patterns were recorded by using a PanAnalytical $X^{\prime}$ Pert 3 MRD material research diffractometer (MRD) with $\mathrm{Cu}_{\mathrm{k} \alpha} \mathrm{X}$-ray radiation $(\lambda=1.5418 \AA)$ at an incident angle of $0.58^{\circ}$. FTIR spectra were acquired with a Bruker Alpha PlatinumATR spectrometer over the wavenumber range $4000-400 \mathrm{~cm}^{-1}$. An FEI-Quanta 200 FEG ESEM was used for imaging and EDAX analysis, operated at $5 \mathrm{kV}$ beam voltage for imaging and $30 \mathrm{kV}$ for EDAX. XPS analysis was performed on a Thermo Scientific K-Alpha X-ray photoelectron spectrometer system with an $\mathrm{Al}_{\kappa \alpha}$ microfocused monochromator source operated at $400 \mathrm{~mm}$ spot size and $h \gamma=$ $1486.6 \mathrm{eV}$ accompanied by a flood gun, $200 \mathrm{eV}$ for survey scans and $30 \mathrm{eV}$ for individual scans. Origin Pro 8.5 software was used to plot and analyze the results.

\section{Acknowledgements}

The authors thank the Science and Technology Council of Turkey, TUBITAK (Project No. 215Z249) for financial support. E.U. thanks TUBITAK for support (Project No. 1929B011500059). Y.D. acknowledges ECOSTBio (CM 1305) for support and thanks the M.N. Parlar Foundation, BAGEP, and TÜBA-GEBIP for young investigator awards. TUBITAK TRGRID infrastructure is gratefully acknowledged for HPC resources. We also thank Prof. Burak Ülgüt for helpful discussions on electrochemistry.

\section{Conflict of interest}

The authors declare no conflict of interest.

Keywords: cyanides - density functional calculations electrocatalysis · Prussian Blue · water oxidation

[1] N. S. Lewis, D. G. Nocera, Proc. Natl. Acad. Sci. USA 2006, 103, 1572915735.

[2] A. Llobet, F. Meyer, Angew. Chem. Int. Ed. 2011, 50, A30-A33.

[3] N. S. Lewis, Science 2016, 351, aad1920.

[4] J. Marshall, Nature 2014, 510, 22-24.

[5] J. R. McKone, N. S. Lewis, H. B. Gray, Chem. Mater. 2014, 26, 407-414.

[6] M. G. Walter, E. L. Warren, J. R. McKone, S. W. Boettcher, Q. Mi, E. A. Santori, N. S. Lewis, Chem. Rev. 2010, 110, 6446-6473.

[7] K. J. Young, L. A. Martini, R. L. Milot, R. C. Snoeberger, V. S. Batista, C. A Schmuttenmaer, R. H. Crabtree, G. W. Brudvig, Coord. Chem. Rev. 2012, 256, 2503-2520.

[8] M. E. G. Lyons, M. P. Brandon, J. Electroanal. Chem. 2010, 641, 119-130.

[9] R. D. L. Smith, M. S. Prévot, R. D. Fagan, Z. Zhang, P. A. Sedach, M. K. J. Siu, S. Trudel, C. P. Berlinguette, Science 2013, 340, 60-63.

[10] Y. Surendranath, M. Dinca, D. G. Nocera, J. Am. Chem. Soc. 2009, 131, $2615-2620$

[11] S. Jung, C. C. L. McCrory, I. M. Ferrer, J. C. Peters, T. F. Jaramillo, J. Mater. Chem. A 2016, 4, 3068-3076.

[12] C. C. L. McCrory, S. Jung, I. M. Ferrer, S. M. Chatman, J. C. Peters, T. F. Jaramillo, J. Am. Chem. Soc. 2015, 137, 4347-4357.
[13] Gurudayal, D. Sabba, M. H. Kumar, L. H. Wong, J. Barber, M. Grätzel, N. Mathews, Nano Lett. 2015, 15, 3833-3839.

[14] A. Kudo, H. Kato, S. Nakagawa, J. Phys. Chem. B 2000, 104, 571-575.

[15] J. Suntivich, K. J. May, H. A. Gasteiger, J. B. Goodenough, Y. Shao-Horn, Science 2011, 334, 1383-1385.

[16] Y. Zhang, C. Zhao, X. Dai, H. Lin, B. Cui, J. Li, J. Power Sources 2013, 243, $908-912$.

[17] L. G. Bloor, P. I. Molina, M. D. Symes, L. Cronin, J. Am. Chem. Soc. 2014, 136, 3304-3311.

[18] T. Reier, M. Oezaslan, P. Strasser, ACS Catal. 2012, 2, 1765-1772.

[19] B. Nepal, S. Das, Angew. Chem. Int. Ed. 2013, 52, 7224-7227; Angew. Chem. 2013, 125, 7365-7368.

[20] Y. Gong, Z. Hao, J. Meng, H. Shi, P. Jiang, M. Zhang, J. Lin, ChemPlusChem 2014, 79, 266-277.

[21] Y. Matsumoto, E. Sato, Mater. Chem. Phys. 1986, 14, 397-426.

[22] D. E. Hall, J. Electrochem. Soc. 1985, 132, 41C-48C.

[23] J. R. Galán-Mascarós, ChemElectroChem 2015, 2, 37-50.

[24] C. C. L. McCrory, S. Jung, J. C. Peters, T. F. Jaramillo, J. Am. Chem. Soc. 2013, 135, 16977-16987.

[25] Z. Chen, A. R. Rathmell, S. Ye, A. R. Wilson, B. J. Wiley, Angew. Chem. Int. Ed. 2013, 52, 13708-13711; Angew. Chem. 2013, 125, 13953-13956.

[26] D. Ressnig, M. Shalom, J. Patscheider, R. Moré, F. Evangelisti, M. Antonietti, G. R. Patzke, J. Mater. Chem. A 2015, 3, 5072-5082.

[27] S. V. K. Nune, A. T. Basaran, E. Ülker, R. Mishra, F. Karadas, ChemCatChem 2017, 9, 300-307.

[28] S. Pintado, S. Goberna-Ferron, E. C. Escudero-Adan, J. R. Galan-Mascaros, J. Am. Chem. Soc. 2013, 135, 13270-13273.

[29] F. Hegner, I. Herraiz-Cardona, D. Cardenas-Morcoso, N. Lopez, J. R. Galan-Mascaros, S. Gimenez, ACS Appl. Mater. Interfaces 2017, 9, 37671 37681.

[30] F. Hegner, D. C.-M. Cardenas-Morcoso, S. Gimenez, N. Lopez, J. R. GalanMascaros, ChemSusChem 2017, 10, $4552-4560$.

[31] S. Goberna-Ferrón, W. Y. Hernadez, B. Rodríguez-García, J. R. Galan-Mascaros, ACS Catal. 2014, 4, 1637-1641.

[32] M. Aksoy, S. V. K. Nune, F. Karadas, Inorg. Chem. 2016, 55, 4301-4307.

[33] L. Han, P. Tang, Á. Reyes-Carmona, B. Rodríguez-García, M. Torréns, J. R. Morante, J. Arbiol, J. R. Galan-Mascaros, J. Am. Chem. Soc. 2016, 138, $16037-16045$.

[34] Y. Yamada, K. Oyama, R. Gates, S. Fukuzumi, Angew. Chem. Int. Ed. 2015, 54, 5613-5617; Angew. Chem. 2015, 127, 5705-5709.

[35] Y. Yamada, M. Yoneda, S. Fukuzumi, Chem. Eur. J. 2013, 19, 11733 11741.

[36] Y. Yamada, K. Oyama, T. Suenobu, S. Fukuzumi, S. Fukuzumi, Chem. Commun. 2017, 53, 3418-3421.

[37] W. Kohn, A. D. Becke, R. G. Parr, J. Phys. Chem. 1996, 100, 12974-12980.

[38] R. G. Parr, W. Yang, Density-Functional Theory of Atoms and Molecules, Oxford University Press, New York, 1989.

[39] D. J. Wasylenko, C. Ganesamoorthy, J. Borau-Garcia, C. P. Berlinguette, Chem. Commun. 2011, 47, 4249-4251.

[40] K. Nakamoto, Infrared and Raman Spectra of Inorganic and Coordination Compounds Part B: Applications in Coordination, Organometallic, and Bioinorganic Chemistry, Wiley, Hoboken, 2009.

[41] R. O. Lezna, R. Romagnoli, N. R. de Tacconi, K. Rajeshwar, J. Phys. Chem. B 2002, 106, 3612-3621.

[42] D. W. Crandell, S. Ghosh, C. P. Berlinguette, M.-H. Baik, ChemSusChem $2015,8,844-852$.

[43] B. Wang, Y.-M. Lee, W.-Y. Tcho, S. Tussupbayev, S.-T. Kim, Y. Kim, M. S. Seo, K.-B. Cho, Y. Dede, B. C. Keegan, T. Ogura, S. H. Kim, T. Ohta, M.-H. Baik, K. Ray, J. Shearer, W. Nam, Nat. Commun. 2017, 8, 14839.

Manuscript received: October 17, 2017

Accepted manuscript online: November 4, 2017

Version of record online: January 4, 2018 